\title{
Anatomia e fisiologia de sementes de Peltophorum dubium (Spreng.) Taub. submetidas ao armazenamento
}

\author{
Anatomy and physiology of seeds of Peltophorum dubium (Spreng.) Taub. \\ subjected to storage
}

\author{
Evelin Maria Müller ${ }^{\mathrm{I}}$, Maiara Iadwizak Ribeiro ${ }^{\mathrm{II}}$, \\ Shirley Martins Silva ${ }^{\text {III }}$, Jaqueline Malagutti Corsato ${ }^{\text {III, }}$ \\ Andréa Maria Teixeira Fortes ${ }^{\mathrm{III}}$
}

\begin{abstract}
Resumo
O estudo objetivou avaliar os aspectos anatômicos e o comportamento fisiológico de sementes de Peltophorum dubium (Spreng.) Taub. durante o armazenamento, submetidas à ação de tratamentos para superação da dormência. Os frutos maduros foram beneficiados e as sementes armazenadas à temperatura de $5^{\circ} \mathrm{C}$ por um período de 360 dias e, posteriormente, submetidas a tratamentos para superação da dormência: (T1 - sem escarificação, T2 - escarificação mecânica e T3 - escarificação química com ácido sulfúrico por 10 minutos). Em intervalos pré-estabelecidos, as sementes foram avaliadas por meio da análise anatômica do tegumento e pelo teste de germinação. As variáveis analisadas foram anatomia do tegumento, porcentagem de germinação, índice de velocidade de germinação e correlação de Pearson entre a espessura do tegumento e as variáveis fisiológicas. Para as análises anatômicas, as sementes foram fixadas, inclusas e seccionadas em micrótomo. A espessura do tegumento das sementes foi mensurada por meio de imagens das secções transversais. O teste de germinação foi conduzido com quatro repetições de 25 sementes, realizado em papel germitest à temperatura constante de $25^{\circ} \mathrm{C}$ com fotoperíodo de 12 horas. O delineamento experimental foi inteiramente casualizado em esquema fatorial $5 \times 3$ (lotes armazenamento e tratamentos para superação da dormência) e as médias comparadas pelo teste de Skott-Knott a $5 \%$ de probabilidade. As análises anatômicas demonstraram perda de resistência física das estruturas do tegumento ao longo do armazenamento. A porcentagem de germinação durante o armazenamento não diferiu significativamente entre os tratamentos, entretanto o índice de velocidade de germinação aumentou e forma significativa quando associado a tratamentos de superação da dormência (T2. 7,08- sementes não armazenadas e 9,29-armazenadas 360 dias; T3. 6,01-sementes não armazenadas e 9,42-armazenadas 360 dias). Foram obtidas correlações significativas entre a espessura do tegumento e as variáveis fisiológicas analisadas. $\mathrm{O}$ armazenamento, por até 360 dias, promoveu modificações anatômicas tegumentares, manteve o alto percentual germinativo das sementes de Peltophorum dubium e, quando associado aos tratamentos de superação da dormência, facilitou a ação destes a partir de 180 dias de armazenagem, aumentando o índice de velocidade de germinação.
\end{abstract}

Palavras-chave: Canafístula; Dormência física; Germinação; Sementes florestais

Bióloga, Me., Pesquisador/Procurador Institucional do Centro Universitário Assis Gurgacz, Av. das Torres, 500 Bairro Loteamento FAG, CEP 85806-095, Cascavel (PR), Brasil. evelinmuller.bio@hotmail.com (ORCID: 0000-0002-9848-6226)

II Bióloga, Me., Doutoranda em Biodiversidade Vegetal e Meio Ambiente, Departamento de Sementes, Instituto de Botânica de São Paulo, Av. Miguel Stefano 3687, Bairro Água Funda, CEP 04301-902, São Paulo (SP), Brasil. maiara.iadwizak@gmail.com (ORCID: 0000-0003-2977-5291)

III Biólogas, Dr., Professores da Universidade Estadual do Oeste do Paraná, Rua Universitária, 1619, Bairro Universitário, CEP 85819-170, Cascavel (PR), Brasil. andrea.fortes@unioeste.br (ORCID: 0000-0002-2836-9331) / jaque_corsato@hotmail.com (ORCID: 0000-0002-0076-8656) / shirley.silva@ unioeste.br (ORCID: 0000-0002-7696-8865) 


\begin{abstract}
The objective of this study was to evaluate the anatomical aspects and the physiological behavior of seeds of Peltophorum dubium (Spreng.) Taub. during storage and while undergoing treatments to overcome dormancy. Mature fruits were collected and seeds stored at $5^{\circ} \mathrm{C}$ for a period of 360 days and later submitted to treatments to overcome dormancy: T1 - without scarification, T2 - mechanical scarification and T3 - chemical scarification with sulfuric acid for 10 minutes. At pre-established intervals, the seeds were evaluated through an anatomical analysis of the tegument and a germination test. The variables analyzed were tegument anatomy, germination percentage, germination speed index and Pearson correlation between tegument thickness and physiological variables. For the anatomical analyses, the seeds were fixed, embedded, and sectioned on a microtome. The thickness of the tegument was measured from the images of the cross sections. The germination test was conducted with four replicates of 25 seeds, carried out on germitest paper at $25^{\circ} \mathrm{C}$ with photoperiod of 12 hours. The experimental design was completely randomized in a $5 \times 3$ factorial scheme (storage and overcoming dormancy treatment groups), and the means were compared by the Skott-Knott test at 5\% probability. The anatomical analysis showed loss of physical resistance of the tegumentary structures during storage. The percentage of germination for the treatments during storage did not differ significantly, however, the rate of germination showed a significant increase when associated with treatments for overcoming dormancy (T2: 7.08 - seeds not stored and 9.29- stored 360 days; T3: 6.01-seeds not stored and 9.42-stored 360 days). Significant correlations were obtained between the thickness of the tegument and the physiological variables analyzed. Storage for up to 360 days promoted tegumentary anatomical modifications, maintained a high germination percentage of the seeds of Peltophorum dubium, and, when associated with treatments for overcoming dormancy, facilitated their action from 180 days of storage, increasing the rate of germination.
\end{abstract}

Keywords: Canafistula; Physical dormancy; Germination; Forest seeds

\title{
Introdução
}

A presença de formações naturais é indispensável na integração e preservação da biodiversidade e na manutenção dos ecossistemas (BARBOSA et al., 2003). Nesse contexto, a restauração de áreas degradadas com espécies nativas é uma alternativa importante para promover a conservação desses ecossistemas, já que em decorrência da grande exploração dos recursos naturais, os remanescentes florestais no Brasil foram fragmentados e reduzidos em relação às suas áreas originais (SCREMIN-DIAS et al., 2006).

Em consequência da necessidade de restauração da vegetação, a demanda por sementes e mudas de espécies nativas está crescendo consideravelmente (SARMENTO; VILLELA, 2010).Para obtenção de sucesso na utilização de sementes, alguns fatores como uma germinação rápida e uniforme, seguida da emergência das plântulas são etapas chaves, porque quanto maior o tempo de emergência da plântula, mais vulnerável a mesma estará em função da exposição às condições adversas do ambiente (MARTINS et al., 2009).

Biologicamente, para que ocorra a germinação, é necessário que alguns fatores como disponibilidade hídrica, temperatura, oxigênio e luminosidade estejam presentes, entretanto, sementes de algumas espécies, mesmo em condições favoráveis do meio, acabam não germinando pelo fato de apresentarem algum tipo de dormência (BEWLEY et al., 2013).

Do ponto de vista ecológico, a dormência é um fator positivo, uma vez que, por meio dela, a distribuição heterogênea da germinação ao longo do tempo e do espaço é possível, maximizando a sobrevivência de novas plântulas formadas em seu habitat natural, característica que, provavelmente, foi adquirida durante a evolução pela seleção natural, por meio da capacidade de sobreviver em ambientes adversos, tais como calor, frio ou seca (BEWLEY et al., 2013; HILHORST, 2007). Porém, em relação à produção de mudas para a restauração de áreas degradadas, a dormência dificulta a sincronização da germinação das sementes em viveiros, sendo necessária a utilização de métodos para superá-la para que a produção ocorra com sucesso (MARTINS; MACHADO; NAKAGAWA, 2008). 
$\mathrm{Na}$ família Fabaceae, a causa mais comum de dormência em sementes é a impermeabilidade do tegumento, caracterizada como dormência exógena-física, em que os envoltórios conferem determinada resistência à entrada de água e/ou gases ao embrião, dificultando o início da hidratação e, consequentemente, do processo germinativo (BEWLEY et al., 2013).De acordo com Baskin e Baskin (2014), a superação da dormência física ocorre mediante a permeabilidade do tegumento e, esta ação em ambientes naturais, pode se dar por meio de diferentes estruturas. Na família Fabaceae, o estrofíolo (carúncula), a rachadura hilar e a micrópila (HU et al.,2009) são citadas como estruturas anatômicas que permitem a entrada de água na semente.

A espécie em estudo, Peltophorum dubium (Spreng.) Taub., conhecida popularmente como Canafístula, pertencente à família Fabaceae, é nativa com ampla ocorrência no Brasil, desde o Estado da Bahia ao Rio Grande do Sul. Entretanto, já tem ameaça de extinção em alguns estados do país, como São Paulo. Possui floração de outubro a fevereiro e frutificação entre os meses de abril e maio, sendo característica da Floresta Estacional Semidecidual e indicada para a restauração de áreas degradadas e matas ciliares (CARVALHO, 2010; MATTEI; ROSENTHAL, 2002). É uma espécie caducifólia classificada como pioneira ou secundária inicial devido a sua rusticidade, sendo comumente encontrada colonizando pastagens, ocupando clareiras e bordas de mata. Tem rápido crescimento, o que auxilia na restauração de áreas degradadas (DUTRA et al., 2013), suas sementes possuem comportamento ortodoxo e dormência física, imposto pelo tegumento impermeável à água e gases, impedindo a hidratação e, consequentemente, a germinação (PEREIRA; LAURA; SOUZA, 2013).

As espécies florestais apresentam, em geral, uma produção irregular de sementes anualmente, além de, muitas vezes, não serem utilizadas imediatamente após a coleta, por isso necessitam ser armazenadas, a fim de manter a viabilidade para utilização futura (KISSMANN et al., 2009). Portanto, a ação de tratamentos para superação da dormência pode ter a eficácia aprimorada para algumas espécies, quando submetidas à armazenagem. No entanto, deve-se levar em conta que essa prática pode variar dependendo da intensidade da dormência do lote de sementes, não eliminando a necessidade da aplicação de tratamentos para superação, evitando, assim, problemas de baixa emergência e formação do estande de plantas (LOPES; NASCIMENTO, 2012).

Nesse sentido, a qualidade fisiológica das sementes é um dos aspectos importantes a serem pesquisados, em decorrência de estarem sujeitas a uma série de mudanças degenerativas de origem bioquímica, fisiológica e física após a maturação, as quais estão associadas com a redução do vigor (GUEDES et al., 2009). Souza e Marcos-Filho (2001) mencionaram a estrutura do tegumento da semente como uma condicionante que pode fornecer informações sobre qualidade fisiológica, vigor e viabilidade das sementes, podendo esclarecer sobre o comportamento das mesmas em determinadas condições, inclusive de armazenamento. Ainda, de acordo com Rajjou e Debeaujon (2008), o revestimento da semente, caracterizado pelo tegumento, desempenha funções importantes como a proteção do embrião a estresses durante o armazenamento.

De acordo com Perez, Fanti e Casali (2001), o estudo sobre a germinação das sementes, principalmente em seus aspectos fisiológicos e anatômicos, é um dos fatores responsáveis pela conservação bem sucedida das mesmas e pelo manejo adequado das es pécies. Análises anatômicas e histoquímicas são utilizadas comumente para determinar e localizar barreiras mecânicas e/ou químicas no tegumento de sementes e, assim, orientar métodos de superação de dormência em sementes (FERREIRA; FRANKE; MOÇO, 2011).

Tendo em vista o destaque ecológico, ambiental e econômico da espécie, a relevante utilização desta em projetos de restauração de áreas degradadas, assim como a necessidade de conservação ex situ, o presente estudo objetiva avaliar os aspectos anatômicos e o comportamento fisiológico de sementes de Peltophorum dubium durante o armazenamento, 
submetidas à ação de tratamentos para superação da dormência, buscando determinar técnicas adequadas para o manejo da dormência quando expostas a condições de armazenagem.

\section{Material e métodos}

Os frutos maduros de Peltophorum dubiumforam coletados no mês de abril de 2015 em quatro matrizes, localizadas no Distrito de Sede Alvorada, Cascavel/PR (244' $41.28^{\prime \prime}$; $53^{\circ} 38^{\prime} 38.44^{\prime}$ O), segundo o padrão de maturação proposto por Müller et al. (2016), quando frutos e sementes tinham coloração castanho escuro, mediante classificação da Munsell color charts for plant tissues (MUNSELL, 1976). Em seguida, estes foram beneficiados manualmente e as sementes homogeneizadas, em ambiente de laboratório.

O armazenamento das sementes foi conduzido por um período de 360 dias, as quais foram colocadas em embalagens de papel permeável dentro de recipientes de vidro hermético, com o fundo revestido por sílica gel, vedados com filme de polietileno e acondicionados em condições refrigeradas à temperatura de $5^{\circ} \mathrm{C}$, na ausência de luz, buscando manter um ambiente frio e seco, proposto por Perez et al. (1999).

As avaliações foram realizadas nos seguintes períodos de armazenamento, divididas por lotes: A0 - avaliação inicial (recém colhidas não armazenadas), A1 (armazenadas por 60 dias),A2 (armazenadas por 180 dias), A3 (armazenadas por 300 dias) e A4 (armazenadas por 360 dias). Após cada período, as sementes foram retiradas e submetidas a tratamentos para superação da dormência, sendo: $\mathrm{T}_{1}$ - sem escarificação, $\mathrm{T}_{2}$ - escarificação mecânica com lixa na região oposta da micrópila e $\mathrm{T}_{3}$ - escarificação química com ácido sulfúrico $\left(\mathrm{H}_{2} \mathrm{SO}_{4}\right)$ por 10 minutos (PIROLI et al., 2005). Em seguida, as sementes foram avaliadas pela análise anatômica do tegumento e pelo teste de germinação.

Para a análise anatômica do tegumento, utilizaram-se 15 sementes de cada período de armazenamento, sendo cinco sementes submetidas para cada um dos tratamentos para superação de dormência citados anteriormente. Posteriormente, essas sementes foram seccionadas transversalmente, à mão livre e fixadas em FAA 50\% (formaldeído, ácido acético e etanol) por 48 horas. Após o processo de inclusão das sementes, realizado mediante trocas exaustivas entre Álcool 70\% e Polietilenoglicol 1500 por um período de seis dias, em ambiente de estufa a $60^{\circ} \mathrm{C}$, de acordo com metodologia adaptada de Rupp (1964). Foram realizadas secções transversais em micrótomo rotativo (Leica), as quais foram coradas com azul de Alcian e Fucsina Básica (KRAUS; ARDUIM, 1997). Em seguida, lâminas semipermanentes foram montadas com auxílio de glicerina 50\%. As imagens das secções elaboradas foram capturadas com auxílio de uma câmera digital acoplada ao Fotomicroscópio Olympus Bx70, utilizando o software DP Controller.

Secções anatômicas obtidas à mão livre também foram submetidas a testes microquímicos para identificara presença de lignina por meio da imersão em Floroglucinol Acidificado (Floroglucinol 2\% e Ácido clorídrico 18\%), e a presença de suberina, lipídios, ceras e cutina com a utilização de Sudan III (KRAUS; ARDUIN, 1997). As pranchas anatômicas foram confeccionadas com auxílio do software Macromedia Fireworks 8.

A espessura do tegumento das sementes foi mensurada por meio das imagens das secções transversais, com auxílio do software ImageJ, com escala calibrada, utilizando-se fotos com escala padronizada, cujos resultados foram expressos em micrometros. A partir das médias da espessura do tegumento dos lotes armazenados e submetidos aos tratamentos para superação da dormência, foram calculados os coeficientes de correlação simples de Pearson, entre a espessura, porcentagem e índice de velocidade de germinação das sementes.

Para o teste de germinação, as sementes submetidas aos diferentes períodos 
de armazenamento passaram pelo procedimento de assepsia, imersas em uma solução contendo cinco gotas de detergente e $100 \mathrm{~mL}$ de água destilada por um período de cinco minutos, com posterior enxágue em água corrente até a completa remoção do detergente. Em seguida, foram submetidas aos diferentes tratamentos para superação da dormência citados anteriormente e, logo após, quatro repetições de 25 sementes foram dispostas entre três folhas de papel germitest, umedecidos com água destilada na proporção de 2,5 vezes o seu peso seco e acondicionadas em câmara de germinação do tipo Biochemical Oxigen Demand (B.O.D.), com temperatura constante de $25^{\circ} \mathrm{C}$ e fotoperíodo $12 / 12$ horas (BRASIL, 2013).

A contagem de sementes germinadas foi realizada diariamente a partir do quarto dia para o tratamento $\mathrm{T}_{1}$ e segundo dia para os tratamentos $\mathrm{T}_{2}$ e $\mathrm{T}_{3}$, até $14^{\circ}$ dia para todos os tratamentos (BRASIL, 2013), sendo consideradas, como germinadas, aquelas com comprimento de raiz primária igual ou superior a $2 \mathrm{~mm}$ (HADAS, 1977). A porcentagem e o índice de velocidade de germinação foram calculados de acordo com Maguire (1962).

O delineamento experimental foi inteiramente casualizado (DIC) em esquema fatorial 5x3 (lotes armazenamento x tratamentos para superação da dormência). A fim de atender os pressupostos de normalidade (Shapiro-Wilk) e homocedasticidade (Levene), os dados foram transformados e marco seno $\sqrt{ } \mathrm{x} / 100$. Os resultados obtidos foram submetidos à análise de variância (ANOVA) fatorial e as médias comparadas pelo teste de Skott-Knotta $5 \%$ de probabilidade. Todas as análises foram realizadas com o auxílio do software estatístico Assistat 7.7 Beta.

\section{Resultados e discussão}

O tegumento das sementes intactas de Peltophorum dubium é caracterizado por cutícula espessa sobre uma camada de células paliçadas (macroesclereídes - exostesta), de formato acicular, também designadas como células de Malpighi. Além disso, posicionada na região mediana das células paliçádicas e percorrendo transversalmente toda essa camada, ocorre a linha refrativa, denominada linha lúcida(Figura 1A), que segundo Ferreira, Franke e Moço (2011)indica que abaixo da cutícula ocorrem substâncias hidrofóbicas, como a suberina, responsável por tornar o tegumento impermeável à água. A camada paliçádica composta por macroesclereídes alongadas e fortemente unidas é uma característica comum da família Fabaceae (BASKIN, 2003).

Constata-se, ainda, pela Figura 1A, que internamente à camada paliçádica, observase uma camada de osteoesclereídes, com constrições medianas, marcando conspícuos espaços intercelulares entre si. De acordo com Cutter (1986), as osteoesclereídes se desenvolvem a partir da hipoderme do tegumento externo e, somadas à camada paliçádica, constituem uma característica marcante no que tange à identificação de sementes de leguminosas. Observa-se que abaixo das osteoesclereídes encontra-se a mesotesta, formada por células parenquimáticas irregulares, de formato arredondado, com paredes espessadas, denominadas braquiesclereidese, mais internamente, uma nova camada de osteoesclereídes pode ser identificada sobre a endotesta, juntamente, com resquícios de células do tégmen.

A semente de Peltophorum dubium é exotestal, uma vez que, de acordo com Appezzatoda-Glória e Carmello-Guerreiro(2006), esse tipo de sementeapresentaa principal camada de tecido mecânico na testa, sendo caracterizado, neste caso, pelas células macroesclereídes e osteoesclereídes.Essa característica pode estar intimamente relacionada à dureza, ao menor grau de umidade quando íntegra e a barreira na absorção de água pelas sementes. 
Figura 1 - Aspectos da anatomia do tegumento de sementes de Peltophorum dubium (Spreng.) Taub. submetidas a tratamentos de superação de dormência, em função do tempo de armazenamento

Figure 1 - Aspects of the anatomy of the tegument of seeds of Peltophorum dubium (Spreng.) Taub. subjected to treatments for overcoming dormancy as a function of storage time

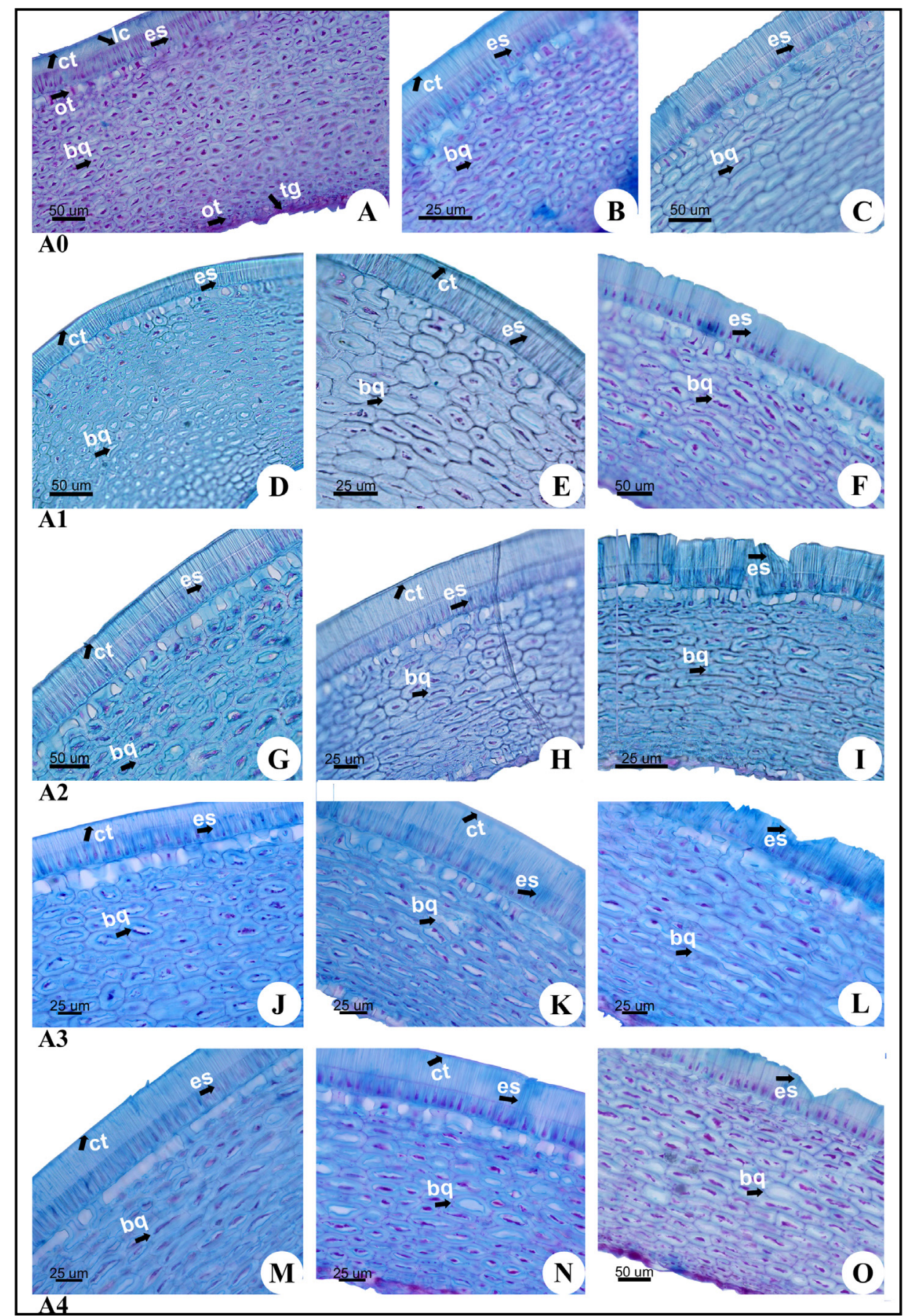

Fonte: Autores (2016)

Em que: (A0) Sementes não armazenadas; (A1)Armazenadas 60 dias; (A2) Armazenadas 180 dias; (A3) Armazenadas 300 dias; (A4)Armazenadas 360 dias; T$_{1}$-Semescarificação (A; D; G; J; M); T -Escarificação mecânica (B; E; H; K; N); T -Escarificação química (C; F; I; L; O). ct: Cutícula; lc: Linha lúcida; bq: Braquiesclereídes; ot: Osteoesclereídes; es: Macroesclereídes; tg: Tégmen. 
A análise microquímica demonstrou ausência de reação para lignina e reação positiva para lipídios, fortemente evidenciada na região cuticular do tegumento. Esse fator atesta a presença de substâncias lipofílicas, com propriedades hidrofóbicas à água, responsáveis por gerar a primeira camada de impermeabilização do tegumento da semente (Figura 2-B) (BASKIN; BASKIN, 2004).

\section{Figura 2 - Análise microquímica do tegumento de sementes de Peltophorum dubium submetidas à coloração com Floroglucinol Acidificado - lignina (A) e Sudan III - lipídeos (B)}

Figure 2 - Microchemical analysis of the tegument of seeds of Peltophorum dubium stained with Acidified Phloroglucinol - lignin (A) and Sudan III - lipid (B)

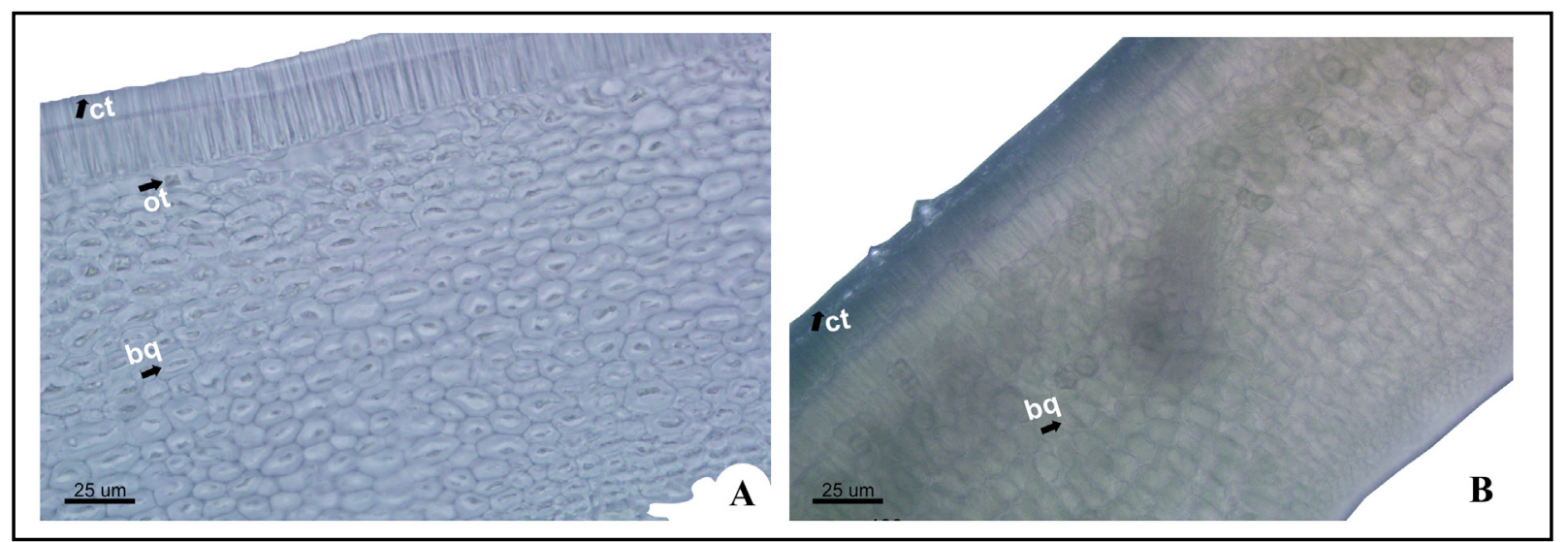

Fonte: Autores (2016)

Em que: ct: Cutícula; bq: Braquiesclereídes; ot: Osteoesclereídes.

Para o tratamento $\mathrm{T}_{1}$ (sem escarificação), diferenças anatômicas tegumentares ocorreram ao longo do armazenamento, sendo detectadas por meio das células braquiesclereídicas que passaram a exibir formato maior e comprimido (Figura 1 - D, G, J e M). Para esse tratamento, a porcentagem e o índice de velocidade de germinação não foram alterados estatisticamente ao longo do armazenamento, sendo, em média, 6,8\% e 0,46 sementes/dia, respectivamente (Tabela 1).

Para o tratamento $\mathrm{T}_{2}$ (escarificação mecânica), diferenças anatômicas foram constatadas evidentemente no lote A1 - 60 dias de armazenamento (Figura 1 - E), em função da mudança de conformação estrutural das células braquiesclereídicas que passaram a apresentar formato comprimido e um aumento no lúmen. Alterações também ocorreram nos lotes A2, A3 e A4 -180,300 e 360 dias de armazenamento, respectivamente (Figura 1 - H, K e N), sendo mais evidentes nos dois últimos, em que as referidas células passaram a apresentar rupturas e afrouxamento das paredes, revelando enfraquecimento e maior permeabilidade do tegumento. A porcentagem de germinação desse tratamento não diferiu estatisticamente para os diferentes lotes, sendo, em média, 95\%, porém o índice de velocidade de germinação apresentou diferença estatística, aumentando até os 180 dias de armazenamento, (7,08 sementes/dia no lote A0 para 9,53 sementes/ dia no lote A3), não diferindo dos demais lotes durante o tempo de armazenagem(Tabela 1).

Ao longo do armazenamento, pode-se observar que para o tratamento $\mathrm{T}_{3}$ (escarificação química)as alterações anatômicas também ocorreram aos 60 dias de armazenamento (lote A1), (Figura 1 - C), persistindo nos demais lotes(Figura1 - F, I, L e O) os quais apresentaram, além da remoção da cutícula, fissuras nas células macroesclereídes, assim como achatamento progressivo e desestruturação nas células braquiesclereídicas com aumento no lúmen. Essas alterações evidenciam um possível processo de perda de resistência física mediante o tratamento ao longo do período. A porcentagem de germinação não diferiu estatisticamente entre os lotes, atingindo 
uma média de $94 \%$, entretanto o índice de velocidade de germinação aumentou significativamente até 180 dias de armazenamento (6,01 sementes/dia lote A0 para 9,54 sementes/dia lote A6), não diferindo dos demais (Tabela 1).

Tabela 1 - Porcentagem de germinação (G) e índice de velocidade de germinação (IVG) de sementes de Peltophorum dubium submetidas a tratamentos para superação de dormência, em função do tempo de armazenamento

Table 1 - Percentage of germination (G) and germination speed index (IVG) of seeds of Peltophorum dubium subjected to treatments for overcoming dormancy as a function of storage time

\begin{tabular}{|c|c|c|c|}
\hline \multirow{2}{*}{$\begin{array}{c}\text { Lotes } \\
\text { armazenamento } \\
\text { (Dias) }\end{array}$} & \multicolumn{3}{|c|}{ G (\%) } \\
\hline & $\begin{array}{c}\mathbf{T}_{1} \\
(\text { Sem escarificação })\end{array}$ & $\begin{array}{c}\mathbf{T}_{2} \\
\text { (Escarificação mecânica) }\end{array}$ & $\begin{array}{c}\mathbf{T}_{3} \\
(\text { Escarificação química })\end{array}$ \\
\hline Lote A0 - 0 & $9,0 \mathrm{aB}$ & $98,0 \mathrm{aA}$ & 96,0 aA \\
\hline Lote A1 - 60 & $7,0 \mathrm{aB}$ & 96,0 aA & $93,0 \mathrm{aA}$ \\
\hline Lote A2 - 180 & $8,0 \mathrm{aB}$ & 96,0 aA & 95,0 aA \\
\hline LoteA3 - 300 & $5,0 \mathrm{aB}$ & $93,0 \mathrm{aA}$ & $95,0 \mathrm{aA}$ \\
\hline Lote A4-360 & $5,0 \mathrm{aB}$ & $92,0 \mathrm{aA}$ & 90,0 aA \\
\hline $\mathrm{CV}(\%)$ & 6,30 & & \\
\hline \multirow{2}{*}{$\begin{array}{c}\text { Lotes } \\
\text { armazenamento } \\
(\text { Dias })\end{array}$} & \multicolumn{3}{|c|}{ IVG (Sementes/dia) } \\
\hline & $\begin{array}{c}\text { T1 } \\
(\text { Sem escarificação })\end{array}$ & $\begin{array}{c}\text { T2 } \\
\text { (Escarificação mecânica) }\end{array}$ & $\begin{array}{c}\text { T3 } \\
\text { (Escarificação química) }\end{array}$ \\
\hline Lote A0 - 0 & $0,36 \mathrm{aC}$ & $7,08 \mathrm{cA}$ & $6,01 \mathrm{cB}$ \\
\hline Lote A1 - 60 & $0,40 \mathrm{aC}$ & $8,23 \mathrm{bA}$ & $6,87 \mathrm{bB}$ \\
\hline Lote A2 - 180 & $0,70 \mathrm{aB}$ & $9,53 \mathrm{aA}$ & $9,54 \mathrm{aA}$ \\
\hline Lote A3-300 & $0,40 \mathrm{aB}$ & 9,33 aA & 9,44 aA \\
\hline LoteA4 - 360 & $0,47 \mathrm{aB}$ & 9,29 aA & 9,42 aA \\
\hline $\mathrm{CV}(\%)$ & 8,36 & & \\
\hline
\end{tabular}

Fonte: Autores (2016)

Médias seguidas pela mesma letra (minúsculas para colunas e maiúsculas para linhas) não diferem estatisticamente entre si pelo Teste de SkottKnottao nível de 5\% de probabilidade. CV\%: Coeficiente de variação.

$\mathrm{O}$ tratamento $\mathrm{T}_{3}$ (escarificação química) foi o que apresentou maiores alterações anatômicas quando comparado com os demais, resultado da ação deste em uma área de superfície maior no tegumento da semente, uma vez que estas ficaram submersas em ácido sulfúrico por 10 minutos, o que ocasionou determinadas desestruturações em diferentes camadas tegumentares, fazendo com que houvesse a passagem da água para o interior da semente. Diferentemente, o tratamento $T_{2}$ (escarificação mecânica) apresentou modificação anatômica apenas para as células braquiesclereídicas, uma vez que esse tratamento é realizado por meio de atrito em superfície abrasiva(lixa), na região oposta da micrópila, não agredindo outras regiões da semente, permitindo a entrada da água por esse local e a ocorrência da embebição, fazendo com que as células braquiesclereídicas apresentem tal formato. Perez (2004) mencionou que em sementes impermeáveis à água, a ação do ácido sulfúrico no enfraquecimento do tegumento pode ser 
resultado da remoção da cutícula e consequente exposição das camadas de macroesclereídes.

Quando se comparam os métodos de superação de dormência dentro dos períodos de armazenamento (Tabela 1), para a porcentagem de germinação, verificou-se que o tratamento $\mathrm{T}_{1}$ (sem escarificação) apresentou as menores médias, diferindo estatisticamente dos demais tratamentos que, por sua vez, não diferenciaram entre si, evidenciando, dessa forma, a presença da dormência física eo destaqueda aplicação dos tratamentos de superação de dormência para o sucesso germinativo da espécie.

Já o índice de velocidade de germinação, para os lotes A0 (sem armazenamento) e A1 (armazenado 60 dias) submetidos ao tratamento $\mathrm{T}_{2}$ (escarificação mecânica) demonstrou as maiores médias, diferenciando-se dos outros tratamentos. Entretanto, a partir do lote A2 (armazenado 180 dias), observou-se que os tratamentos $\mathrm{T}_{2}$ e $\mathrm{T}_{3}$ passaram a não apresentar diferença estatística entre si, diferenciando-se apenas do tratamento $\mathrm{T}_{1}$ (sem escarificação). Mediante isso, supõe-se que a corrosão promovida pelo ácido sulfúrico encontrou menor resistência do tegumento nesse período, possivelmente, em decorrência a maior sensibilidade dessas sementes ao tratamento, promovido pelo armazenamento.

Resultados semelhantes foram encontrados por Ignácio (2013) ao trabalhar com sementes de Balfourodendron riedelianum, as quais apresentaram aumento do índice de velocidade de germinação durante o armazenamento por 12 meses, em decorrência da superação gradativa da dormência das sementes, ao longo do tempo. Do contrário, Biruel, Aguiar e Paula (2007) verificaram que para sementes de Caesalpinia leiostachya, durante o armazenamento, apesar do enfraquecimento do tegumento, ficaram mais resistentes à ação do ácido sulfúrico, demonstrando, dessa forma, que esse comportamento pode variar em função da espécie.

As modificações anatômicas e fisiológicas verificadas ao longo do armazenamento, intensificadas quando em associação aos tratamentos para superação da dormência, possivelmente, sejam em decorrência da aplicação da armazenagem, uma vez que de acordo com Qaderi, Cavers e Bernards (2003), durante esse período ocorrem mudanças físicas e químicas que alteram as forças de tensão do tegumento da semente e, consequentemente, a permeabilidade à água e a gases. De acordo com Jayasuriya et al. (2009), sementes com maior sensibilidade requerem tratamentos de superação de dormência mais suaves e breves, e sementes insensíveis necessitam de tratamentos mais intensos e prolongados.

Alguns trabalhos sugerem que, dependendo da espécie, a superação da dormência física de sementes pode necessitar de uma ou duas etapas e, nesses casos, na primeira etapa, as sementes tornam-se sensíveis aos tratamentos de superação, ainda que permaneçam impermeáveis, e então, na segunda etapa, tornam-se permeáveis após a exposição às condições ambientais adequadas (GAMA-ARACHCHIGE et al., 2013).

A partir desses resultados, pode-se sugerir que a espécie em estudo teve comportamento semelhante, sendo a primeira sensibilização conferida pelo armazenamento, resultando na maior vulnerabilidade das sementes quando submetidas aos tratamentos de superação de dormência, aumentando o índice de velocidade de germinação, ainda que não tenham se tornado totalmente permeáveis. Resultados semelhantes são relatados por Silva, Albuquerque e Silva (2014) para sementes de Parkia pendula, as quais, quando armazenadas em câmara refrigerada e seca por seis meses, e em conjunto de tratamento de superação de dormência, apresentaram aumento da porcentagem de germinação e diminuição do tempo médio de emissão da raiz.

Para a superação de dormência física das sementes, é necessário que o tegumento tornese permeável, e, em ambientes naturais, esse processo é atribuído por mudanças específicas do local, como a variação de temperatura e umidade (BASKIN; BASKIN, 2014). Com base nessas informações, e mediante as respostas anatômicas e fisiológicas deste estudo, sugere-se que, para sementes de Peltophorum dubium, a desestruturação anatômica do tegumento é uma possível rota de passagem de umidade para o seu interior, quando submetidas a condições de ambiente seco, como foi realizado o armazenamento. De acordo com Baskin (2003), é possível que além das estruturas especializadas, a entrada da água ocorra de forma geral ao longo do revestimento da 
semente (tegumento)porque a estrutura e a composição química da testa são diferentes em cada espécie.

Pode-se verificar que a espessura do tegumento das sementes de Peltophorum dubium ao longo do armazenamento, somada aos diferentes tratamentos de superação de dormência, apresentou correlação significativa $(\mathrm{P}<0,05)$ com os parâmetros fisiológicos. Para o tratamento $\mathrm{T}_{1}$ (sem escarificação), a espessura do tegumento com a porcentagem de germinação não obteve correlação significativa, já para o índice de velocidade de germinação a correlação significativa foi negativa de $-0,97$. Aos tratamentos $\mathrm{T}_{2}$ (escarificação mecânica) e $\mathrm{T}_{3}$ (escarificação química), a espessura do tegumento respondeu a correlações positivas de 0,41 e 0,46 respectivamente e o índice de velocidade de germinação para esses tratamentos obtiveram correlações negativas de $-0,91$ e $-0,90$, respectivamente (Tabela 2 ).

Tabela 2 - Coeficientes de correlação simples de Pearson (r) da espessura do tegumento de sementes de Peltophorum dubium, submetidas a tratamentos de superação de dormência, ao longo do armazenamento entre o índice de velocidade de germinação (IVG) e porcentagem de germinação $(G)$

Table 2 - Simple Pearson correlation coefficients (r) of the thickness of the tegument of Peltophorum dubium seeds, subject to treatments for overcoming dormancy, following storage, between the germination speed index (IVG) and germination percentage $(G)$

\begin{tabular}{ccc}
\hline & \multicolumn{2}{c}{ Espessura tegumento $(\mu \mathrm{m})$} \\
\cline { 2 - 3 } Tratamentos & G $(\%)$ & IVG $($ Sementes/dia) \\
\hline T1 (sem escarificação) & $0,06^{\mathrm{ns}}$ & $-0,97^{*}$ \\
T2 (escarificação mecânica) & $0,41^{*}$ & $-0,91^{*}$ \\
T3 (escarificação química) & $0,46^{*}$ & $-0,90^{*}$ \\
\hline
\end{tabular}

Fonte: Autores (2016)

Em que: *: Correlação significativa a 5\% de probabilidade; ns: Correlação não significativa.

Ao analisar a espessura do tegumento das sementes para os diferentes tratamentos para superação de dormência, ao longo do armazenamento, pode-se observar o comportamento decrescente durante o período (Tabela 3). Para o tratamento $\mathrm{T}_{1}$ (sem escarificação), a diminuição da espessura, sem a ação de tratamento de superação, demonstra o efeito direto do armazenamento sobre essa variável, o qual pode ser responsável por responder à alta correlação negativa com o índice de velocidade de germinação das sementes (Tabela 2). Já para os tratamentos $\mathrm{T}_{2}$ (escarificação mecânica) e $\mathrm{T}_{3}$ (escarificação química), observa-se que a diminuição da espessura foi influenciada pela ação dos tratamentos, em especial para $T_{3}$, que diferiu estatisticamente aos 60 dias de armazenamento (lote A1), não diferindo dos demais.

Portanto, verificou-se que, ao longo do armazenamento, conforme a espessura do tegumento diminuiu (Tabela 3), o índice de velocidade de germinação das sementes aumentou (Tabela 1), sustentando a evidência de que as alterações na estrutura do tegumento foram responsáveis pelo aumento dessa variável, quando associado a tratamentos de superação de dormência, porém não implicando necessariamente na porcentagem de germinação das sementes. Popinigis (1985) fez referência aos fatores que condicionam a velocidade de absorção de água, dentre eles as características morfológicas e a composição química do tegumento. De acordo com Marcos-Filho (2015), o tegumento é o principal modulador das interações entre o ambiente externo e as partes internas das sementes, tendo como uma das principais funções o controle da velocidade de hidratação das sementes. 


\section{Tabela 3 - Espessura do tegumento de sementes de Peltophorum dubium submetidas a tratamentos de superação de dormência, em função do tempo de armazenamento}

Table 3 - Tegumentthickness of Peltophorum dubium seeds submitted to scarification treatments as a function of storage time

\begin{tabular}{cccc}
\hline & \multicolumn{3}{c}{ Espessura tegumento $(\mu \mathrm{m})$} \\
Lotes armazenamento \\
\cline { 2 - 4 }$($ Dias $)$ & T1 & T2 & T3 \\
& (Sem escarificação) & (Escarificação mecânica) & (Escarificação química) \\
\hline Lote A0 - 0 & $63,10 \mathrm{aA}$ & $61,62 \mathrm{aB}$ & $53,55 \mathrm{aC}$ \\
Lote A1 - 60 & $61,30 \mathrm{bA}$ & $60,52 \mathrm{bA}$ & $52,17 \mathrm{bB}$ \\
Lote A2 - 180 & $56,87 \mathrm{cA}$ & $57,32 \mathrm{dA}$ & $51,20 \mathrm{bB}$ \\
LoteA3 - 300 & $61,60 \mathrm{bA}$ & $57,55 \mathrm{~dB}$ & $51,70 \mathrm{bC}$ \\
Lote A4 - 360 & $60,80 \mathrm{bA}$ & $59,37 \mathrm{cB}$ & $51,52 \mathrm{bC}$ \\
\hline $\mathrm{CV}(\%)$ & 1,33 & & \\
\hline
\end{tabular}

Fonte: Autores (2016)

Em que: Médias seguidas pela mesma letra (minúsculas para colunas e maiúsculas para linhas) não diferem estatisticamente entre si pelo Teste de Skott Knott ao nível de 5\% de probabilidade. CV\%: Coeficiente de variação.

Resultados semelhantes foram encontrados por Oliveira, Ferreira e Carvalho (2003) trabalhando com sementes de Senna multijuga, os quais verificaram que o armazenamento contribuiu diretamente para o aumento da permeabilidade do tegumento das sementes que possuem dormência física. Ainda de acordo com Bussinguer (2014),o armazenamento de sementes de Pterogyne nitens, associado ao envelhecimento acelerado, demonstrou-se satisfatório no aumento da porcentagem de germinação, primeira contagem de germinação e índice de velocidade, indicando um efeito positivo do armazenamento sobre a superação da dormência física.

Dessa forma, a combinação dos estudos anatômicos e fisiológicos possibilita a formulação de respostas a respeito da superação de dormência, tal como ocorre na natureza, porque em ambientes naturais as sementes não germinam 100\%,e alguns fatores como a alternância de temperaturas, umidade relativa, dentre outros distúrbios ambientais, podem ocorrer resultando na desestruturação tegumentar e superação da dormência física das sementes(CHACHALIS; SMITH, 2000). De acordo com Baskin e Baskin (2004), para algumas espécies com sementes que apresentam dormência física quando expostas a variações sazonais na temperatura e precipitação, em condições ambientais naturais, o período seco pode favorecer a superação da dormência destas, por meio da alteração da estrutura do tegumento, sendo que com a chegada do período úmido, essas sementes passam a adquirir água e germinam.

Contudo, ressalta-se ainda que, de acordo com Gonçalves et al. (2017), a intensidade da dormência de sementes pode variar entre lotes. Estudos ontológicos indicam que a impermeabilidade do tegumento é adquirida na fase final do desenvolvimento das sementes e varia entre sementes da mesma espécie, coletadas em diferentes locais e anos (ROLSTON, 1978), em decorrência das variações ocorridas na duração do dia, nutrição mineral, disponibilidade de água, dentre outros fatores (PEREZ, 2004). Diante disso, para fins de produção de mudas, bem como para a condução do teste de germinação, é recomendável a realização de um teste preliminar para cada lote de sementes, visando definir o tratamento e o período de escarificação a ser adotado, uma vez que a eficiência destes, assim como a resposta obtida pela armazenagem, podem apresentar variações, em decorrência da intensidade da dormência do lote.

Com base nos resultados obtidos neste trabalho, o armazenamento de sementes de 
Peltophorum dubium em condições de ambiente frio e seco, é um método eficiente para conservação do potencial fisiológico da espécie, uma vez que promoveu aumentos significativos na velocidade de germinação das sementes, quando associado a tratamentos para superação de dormência, sendo um fator positivo para acelerar e sincronizar o processo germinativo e a produção de mudas em viveiros, auxiliando, assim, em projetos de restauração de áreas degradadas.

\section{Conclusões}

O armazenamento por até 360 dias promoveu modificações anatômicas tegumentares, manteve o alto percentual germinativo das sementes de Peltophorum dubium. E, quando associado aos tratamentos de superação de dormência, facilitou a ação destes, a partir de 180 dias de armazenagem, aumentando o índice de velocidade de germinação.

\section{Referências}

APPEZZATO-DA-GLÓRIA, B.; CARMELlo-GUERREIRO, S. M. Anatomia vegetal. 2. ed. rev. atual. Viçosa: Universidade Federal de Viçosa, 2006. 438 p.

BARBOSA, L. M. et al. Recuperação florestal com espécies nativas no estado de São Paulo: pesquisas apontam mudanças necessárias. Florestar Estatístico, São Paulo, v. 6, n. 14, p. 28-34, jan. 2003.

BASKIN, C. C. Breaking physical dormancy in seeds - focussing on the lens. New Phytologist, [s.l.], v. 158, n. 2, p. 229-232, May 2003. http://dx.doi.org/10.1046/j.1469-8137.2003.00751.x.

BASKIN, C. C.; BASKIN, J. M. Seeds: ecology, biogeography, and evolution of dormancy and germination. 2. ed. San Diego: Academic Press / Elsevier, 2014. 1600 p.

BASKIN, J. M.; BASKIN, C. C. A classification system for seed dormancy. Seed Science Research, [s.1.], v. 14, n. 1, p. 1-16, mar. 2004. Cambridge University Press (CUP). http://dx.doi.org/10.1079/ssr2003150.

BEWLEY, J. D. et al. Seeds: physiology of development, germination and dormancy. 3. ed. New York: Springer, 2013. $392 \mathrm{p}$.

BIRUEL, R. P.; AGUIAR, I. B.; PAULA, R. C. Germinação de sementes de pau-ferro submetidas a diferentes condições de armazenamento, escarificação química, temperatura e luz. Rev. Bras. Sementes, Londrina, v. 29, n. 3, p. 151-159, 2007. http://dx.doi.org/10.1590/s0101-31222007000300018.

BRASIL. Ministério da Agricultura, Pecuária e Abastecimento. Instruções para análise de sementes de espécies florestais. Brasília: MAPA, 2013. 98 p.

BUSSINGUER, A. P. Avaliação de parâmetros do teste de envelhecimento acelerado para determinação do vigor de sementes de Pterogyne Nitens tul. sob duas condições de armazenamento. 2014. 50 f. Dissertação (Mestrado) - Curso de Ciências Florestais, Departamento de Engenharia Florestal, Universidade de Brasília, Brasília, 2014.

CARVALHO, P. E. R. Espécies arbóreas brasileiras. Brasília: Embrapa, 2010. v.1. 644 p. (Coleção Espécies Arbóreas Brasileiras).

CHACHALIS, D.; SMITH, M. L. Imbibition behavior of soybean (Glycine max L. Merrill) accessions with different testa characteristics. Seed Science and Technology, Bassersdorf, v. 28, n. 2, p. 321-331, 2000.

CUTTER, E. G. Anatomia vegetal. 2. ed. Roca: São Paulo, 1986. 336 p.

DUTRA, T. R. et al. Substratos alternativos e métodos de quebra de dormência para a produção de mudas de canafístula. Ceres, Viçosa, v. 60, n. 1, p. 72-78, jan. 2013. https://doi.org/10.1590/S0034737X2013000100011. 
FERREIRA, N. R.; FRANKE, L. B.; MOÇO, M. C. C. Estudos morfo-anatômicos relacionados à dormência em sementes de Adesmia tristis Vogel (Fabaceae). Rev. Bras. Sementes, Londrina, v. 33, n. 3, p. 447-453, fev. 2011. https://doi.org/10.1590/S0101-31222011000300007

GAMA-ARACHCHIGE, N. S. et al. Quantitative analysis of the thermal requirements for stepwise physical dormancy-break in seeds of the winter annual Geranium carolinianum (Geraniaceae). Annals of Botany, Oxford, v. 111, n. 5, p. 849-858, jan. 2013. http://dx.doi.org/10.1093/aob/mct046.

GONÇALVES, A. F. T. et al. Biometria de frutos, armazenamento e germinação de sementes de Stryphnodendron adstringens (Mart.) Coville. Caderno de Ciências Agrárias, Minas Gerais, v. 9, n.3, p. 38-48, 2017. https://doi.org/10.35699/2447-6218.2017.2985

GUEDES, R. S. et al. Teste de comprimento de plântula na avaliação da qualidade fisiológica de sementes de Erythrina velutina Willd. Semina: Ciências Agrárias, Londrina v. 30, n. 4, p. 793-802, dez. 2009. http://dx.doi.org/10.5433/1679-0359.2009v30n4p793.

HADAS, A. Water uptake and germination of leguminous seeds in soils of changing matric and osmotic water potential. Journal of Experimental Botany, Oxford, v. 28, n. 4, p. 977-985, 1977. http:// dx.doi.org/10.1093/jxb/28.4.977.

HILHORST, H.W. M. Definitions and hypotheses of seed dormancy. In: BRADFORD, K.; NONOGAKI, H. Seed development, dormancy and germination. Oxford: Blackwell Publishing, 2007. 367 p.

HU, X. W. et al. Role of the lens in controlling water uptake in seeds of two Fabaceae (Papilionoideae) species treated with sulphuric acid and hot water. Seed Science Research, Cambridge, v. 19, n. 2, p. 73-80, jun. 2009. http://dx.doi.org/10.1017/s0960258509301099.

IGNÁCIO, V. L. Germinação e conservação de sementes de Balfourodendron riedelianum (Engler) Engler. 2013. 124 f. Tese (Doutorado) - Curso de Programa de Pós-graduação em Agronomia, Centro de Ciências Agrárias, Universidade Estadual do Oeste do Paraná, Marechal Cândido Rondon, 2013.

JAYASURIYA, K. M. G. G. et al. Sensitivity cycling and mechanism of physical dormancy break in seeds of Ipomoea hederacea (Convolvulaceae). International Journal of Plant Sciences, Chicago, v. 170, n. 4, p. 429-443, mai. 2009. http://dx.doi.org/10.1086/597270.

KISSMANN, Camila et al. Germinação e armazenamento de sementes de Albizia hasslerii (Chod.) Burkart. Revista Brasileira de Sementes, Londrina, v. 31, n. 2, p. 104-115, 2009. http://dx.doi.org/10.1590/ s0101-31222009000200012.

KRAUS, J. E.; ARDUIN, M. Manual básico de métodos em morfologia vegetal. Rio de Janeiro: Seropédica, 1997. 198 p.

LOPES, A. C. A.; NASCIMENTO, W. M. Peletização em sementes hortaliças. Brasília: Embrapa, 2012. $28 \mathrm{p}$.

MAGUIRE, J. D. Speed of germination - aid in selection and evaluation for seedling emergence and vigor 1. Crop Science, Madison, v. 2, n. 2, p. 176-177, mar. 1962. http://dx.doi.org/10.2135/cropsci1962.0 011183x000200020033x.

MARCOS-FILHO, J. Fisiologia de sementes de plantas cultivadas. Londrina: Abrates, 2015. 659 p.

MARTINS, C. C. et al. Umedecimento do substrato na emergência e vigor de plântulas de pupunheira. Revista Brasileira de Fruticultura, [s.1.], v. 31, n. 1, p. 224-230, mar. 2009. http://dx.doi. org/10.1590/s0100-29452009000100031.

MARTINS,C.C.;MACHADO,C.G.;NAKAGAWA,J.Temperaturaesubstratoparaotestedegerminação de sementes de barbatimão ((Stryphnodendron adstringens (Mart.) Coville (Leguminosae)). Revista Árvore, Viçosa, v. 32, n. 4, p. 633-639, ago. 2008. Http://dx.doi.org/10.1590/s0100-67622008000400004.

MATTEI, V. L.; ROSENTHAL, M. D. Semeadura direta de canafístula (Peltophorum dubium (Spreng.) taub. no enriquecimento de capoeiras. Revista Árvore, Viçosa, v. 26, n. 6, p. 649-654, nov. 2002. Http:// 
dx.doi.org/10.1590/s0100-67622002000600001.

MÜLLER, E. M. et al. Maturação e dormência em sementes de Peltophorum dubium (Spreng) Taub. de diferentes árvores matrizes. Iheringia-Série Botânica, Porto Alegre, v.71, n. 3, 2016.

MUNSELL, A. H. Munsell color charts for plant tissues. Munsell Color Company: Baltimore, 1976.

OLIVEIRA, L. M.; FERREIRA, R. A.; CARVALHO, M. L. M. Germinação de sementes de Senna multijuga (Rich.) Irwin et Barn., sob diferentes condições de radiação luminosa e temperaturas. Ciência Agronômica, Fortaleza, v. 34, n. 2, p. 213-218, 2003.

PEREIRA, S. R.; LAURA, V. A.; SOUZA, A. L. T. Superação de dormência de sementes como estratégia para restauração florestal de pastagem tropical. Pesquisa Agropecuária Brasileira, Brasília, v. 48, n. 2, p. 148-156, fev. 2013. Http://dx.doi.org/10.1590/s0100-204x2013000200004.

PEREZ, S. C. J. G. A. Envoltórios. In: FERREIRA, A. G.; BORGHETTI, F. (Org.). Germinação: do básico ao aplicado. Porto Alegre: Artmed, 2004. p. 125-134.

PEREZ, S. C. J. G. A.; FANTI, S. C.; CASALI, C. A. Influência da luz na germinação de sementes de canafístula submetidas ao estresse hídrico. Bragantia, Campinas, v. 60, n. 3, p. 155-166, 2001. http:// dx.doi.org/10.1590/s0006-87052001000300002.

PEREZ, S. C. J. G. A.; FANTI, S. C.; CASALI, C. A. Influência do armazenamento, substrato, envelhecimento precoce e profundidade de semeadura na germinação de canafístula. Bragantia, Campinas, v. 58, n. 1, p. 57-68, 1999. http://dx.doi.org/10.1590/s0006-87051999000100008.

PIROLI, E. L. et al. Germinação de sementes de Canafístula (Peltophorum dubium (Spreng.) Taub). tratadas para superação da dormência. Colloquium Agrariae, Presidente Prudente, v. 1, n. 1, p. 13-18, set. 2005.

POPINIGIS, F. Fisiologia da semente. 2. ed. Brasília: AGIPLAN, 1985. 289 p.

QADERI, M. M.; CAVERS, P. B.; BERNARDS, M. A. Pre- and post-dispersal factors regulate germination patterns and structural characteristics of Scotch thistle (Onopordum acanthium) cypselas. New Phytologist, [s.l.], v. 159, n. 1, p. 263-278, jul. 2003. Http://dx.doi.org/10.1046/j.14698137.2003.00777.x.

RAJJOU, L.; DEBEAUJON, I. Seed longevity: survival and maintenance of high germination ability of dry seeds. Comptes Rendus Biologies, [s.1.], v. 331, n. 10, p. 796-805, out. 2008. http://dx.doi.org/10.1016/j. crvi.2008.07.021.

ROLSTON, M. Philip. Water impermeable seed dormancy. The Botanical Review, [s.l.], v. 44, n. 3, p. 365-396, jul. 1978. http://dx.doi.org/10.1007/bf02957854.

RUPP, P. Polyglykol als einbettungsmedium zum scheneiden botanischer präparate. Mikrokosmos, Stuttgart, v. 53, n. 1, p. 123-128, 1964.

SARMENTO, M. B.; VILLELA, F. A. Sementes de espécies florestais nativas do sul do Brasil. Informativo Abrates, Londrina, v. 20, n. 1, p. 39-44, 2010.

SCREMIN-DIAS, E. et al. Produção de sementes de espécies florestais nativas: manual. Campo Grande: UFMS, 2006. 43 p. (Rede de sementes do Pantanal, v. 1).

SILVA, J. R. O.; ALBUQUERQUE, M. C. F.; SILVA, I. C. O. Armazenamento de sementes de Parkia pendula (Willd.) Benth. ex Walp. (FABACEAE) em diferentes embalagens e ambientes. Floresta e Ambiente, [s.1.], v. 21, n. 4, p. 457-467, out. 2014. http://dx.doi.org/10.1590/2179-8087.054013.

SOUZA, F. H. D.; MARCOS-FILHO, J. The seed coat as a modulator of seed-environment relationships in Fabaceae. Revista Brasileira de Botânica, São Paulo, v. 24, n. 4. p. 365-375, dez. 2001. http://dx.doi. org/10.1590/s0100-84042001000400002. 